\title{
Gastric Carcinoma: A Clinical Study
}

\author{
Author \\ Dr Santosh M Patil \\ Study done in Department of General Surgery, Justice K S Hegde Medical Academy, Mangalore \\ Corresponding Author \\ Dr Santosh M Patil \\ Assistant Professor, Department Of General Surgery \\ M N R Medical College and Hospital, Sangareddy, Telangana \\ Email:drsmp456@gmail.com, Contact number: +919886745600
}

\begin{abstract}
This is a clinical study on 41 gastric neoplasm subjects diagnosed by upper gastrointestinal endoscopy. These patients were evaluated with set of questions and monitored for clinical presentation with risk factors till the treatment. Forty one cases of carcinoma stomach which were serially monitored for signs and symptoms. It was noted patients had Dyspepsia in 18(43.9\%) patients, pain abdomen in 37(90.2\%), vomiting in 35(85.4\%), loss of weight and loss of appetite in 39(95.1\%) and mass per abdomen in 1 patient (2.4\%)Pallor noted in 32 (78\%) patients, mass palpable in 17 (41.5\%) patients, liver palpable in 8 (19.5\%) patients, ascites in 10 (24.4\%) patients and Virchow's node positive in $6(14.6 \%)$ patients. Smoking and alcohol consumption were predisposing risk factors with 21 (51.2\%), 17 (41.5\%) respectively. This study helps to identify the common symptoms and signs of the Gastric cancer, which can be picked up by thorough clinical evaluation, which also helps patients to diagnose and subject to accurate treatment immediately thus reducing the morbidity and mortality.
\end{abstract}

Key Words: Gastric carcinoma; symptoms; diagnosis.

\section{Introduction}

Gastric cancer is one of the most common malignancies worldwide ${ }^{1}$. It tops the list of cancer related death in many countries of the world including countries in Asia. It is the fifth most common cancer among males and seventh among females in India ${ }^{2}$ with the highest rate being in Chennai registry ${ }^{3-5}$. Gastric carcinogenesis is a multifactorial process ${ }^{6}$. In 400 BC, Hippocrates described about black vomiting in a patient and "KARKINOMA" of the stomach. NapoleonBonaparte was found, at autopsy, to have a largegastric cancer that had perforated and, in fact, several members of the Bonaparte family were reported to have died from gastric cancer ${ }^{8}$ As there is historical importance, immense research has been done on gastric carcinoma. More recently, Marshall and Warrenwere awarded the 2005 Nobel Prize in Medicine and Physiology, in part for their discovery of Helicobacter pylori and its causative role in gastric cancer ${ }^{9}$. Recently it has been found that, there may be a relationship exists between H.pylori infection and gastric carcinoma. H. pylori cause chronic gastritis, 
gastric atrophy and intestinal metaplasia ultimately leading to gastric malignancy ${ }^{10}$. Helicobacter pylori infection is associated with an approximately two-fold increased risk of developing gastric cancer ${ }^{11-13}$. Pylori $\mathrm{H}$ have been categorized as a "Group-1 human carcinogen" by the International Agency for Research on Cancer 14

\section{Materials and Methods}

41 cases of carcinoma stomach which were admitted during October 2008 till April 2010 at Justice K.S.Hegde Charitable Hospital, Mangalore are included.

\section{Inclusion criteria}

- All patients diagnosed to have carcinoma stomach confirmed by histopathology

- Patients who gave consent for procedures were included.

\section{Exclusion criteria}

- Patients with chronic disease

- Immunosuppressed

- Patients using non-steroid antiinflammatory

- Previous radiotherapy/chemotherapy

- Patients not willing/ refuse to give consent were excluded from the study.

\section{Statistical Analysis}

Descriptive statistics were used for analyzing the data using SPSS version 20 and results were presented in percentage and simple frequency.

\section{Results}

\section{Age distribution}

In the present study age distribution was between 37 years to 81 years. Table 1

Table: 1 Age distribution

\begin{tabular}{|l|c|c|}
\hline Age & Frequency & Percentage \\
\hline $30-39$ & 3 & 7.3 \\
\hline $40-49$ & 7 & 17 \\
\hline $50-59$ & 14 & 34.2 \\
\hline $60-69$ & 10 & 24.4 \\
\hline $70-79$ & 5 & 12.2 \\
\hline $80+$ & 2 & 4.9 \\
\hline
\end{tabular}

Sex

In the study $26(63.4 \%)$ patients were male and $15(36.6 \%)$ were females. There is male preponderance in this study. Table 2

Table: 2 Sex distributions

\begin{tabular}{|l|l|l|}
\hline & Frequency & Percentage \\
\hline FEMALE & 15 & 36.6 \\
\hline MALE & 26 & 63.4 \\
\hline Total & 41 & 100 \\
\hline
\end{tabular}

\section{Symptoms}

In the study $18(43.9 \%)$ patients presented with dyspepsia, 37(90.2\%) presented with pain abdomen, 35(85.4\%) patients presented with vomiting, 39(95.1\%) patients presented with loss of weight and loss of appetite and mass per abdomen in 1 patient $(2.4 \%)$. Table 3

Table: 3 Symptoms

\begin{tabular}{|l|l|c|c|}
\hline & SYMPTOMS & Present & Absent \\
\hline 1 & PAIN ABDOMEN & $37(90.2 \%)$ & $4(9.8 \%)$ \\
\hline 2 & VOMITING & $35(85.4 \%)$ & $6(14.6 \%)$ \\
\hline 3 & DYSPEPSIA & $18(43.9 \%)$ & $23(56.1 \%)$ \\
\hline 4 & $\begin{array}{l}\text { LOSS OF WEIGHT \& LOSS } \\
\text { OF APPETITE }\end{array}$ & $39(95.1 \%)$ & $2(4.9 \%)$ \\
\hline 5 & MASS ABDOMEN & $1(2.4 \%)$ & $40(97.6 \%)$ \\
\hline
\end{tabular}




\section{Signs}

In this study pallor was present in $32(78 \%)$ patients, mass palpable in $17(41.5 \%)$ patients, liver palpable in $8(19.5 \%)$ patients, ascites in 10 (24.4\%) patients and Virchow's node positive in 6 (14.6\%) patients.Table 4

Table: 4 Clinical examinations

\begin{tabular}{|l|c|c|c|}
\hline & Clinical examination & Present & Absent \\
\hline 1 & PALLOR & $32(78 \%)$ & $9(22 \%)$ \\
\hline 2 & MASS PER ABDOMEN & $17(41.5 \%)$ & $24(58.5 \%)$ \\
\hline 3 & HEPATOMEGALY & $8(19.5 \%)$ & $33(80.5 \%)$ \\
\hline 4 & ASCITES & $10(24.4 \%)$ & $31(75.6 \%)$ \\
\hline 5 & VIRCHOWS NODE & $6(14.6 \%)$ & $35(85.4 \%)$ \\
\hline
\end{tabular}

\section{Risk factors}

In this study of 41 patients $21(51.2 \%)$ were smokers and $17(41.5 \%)$ patients had history of alcohol consumption. None of the patients had family history of gastric cancer.Table 5

Table: 5 Risk factors

\begin{tabular}{|l|c|c|c|}
\hline & RISK FACTORS & YES & NO \\
\hline 1 & SMOKING & $21(51.2 \%)$ & $20(48.8 \%)$ \\
\hline 2 & ALCOHOL & $17(41.5 \%)$ & $24(58.5 \%)$ \\
\hline 3 & FAMILY HISTORY & $0(0 \%)$ & $41(100 \%)$ \\
\hline
\end{tabular}

\section{Discussion}

Gastric cancer has an extremely poor prognosis because of the aggressive nature of the disease. Once clinical manifestations appear, gastric cancer has poor prognosis where stage I disease has about 60 to $80 \%$ five-year survival, this can be as low as a less than $5 \%$ five-year survival rate in stage $\mathrm{IV}^{15}$ using currently available treatments, surgery and radio-chemotherapy. Therefore, the challenge in gastric cancer is to prevent its development by early detection and treatment of pre-cancerous lesions and elimination of known risk factors. In order to achieve this goal, it is necessary to understand the clinical presentation of gastric carcinoma.

To improve the diagnosis of gastric cancer, age is an important factor. The risk of gastric cancer gradually increases with increase in age. Our study showed a similar pattern of high incidence in the age group of 50-59 years which had 14
(34.2\%) patients. Male sex is also significantly associated with gastric cancer where 26 patients (63.4\%) were affected ${ }^{16-19}$.

On clinical evaluation of patients the following symptoms were predominantly noted. Loss of appetite and loss of weight seen in $95.1 \%$ (37), pain abdomen in $90.2 \%$ (37), which was seen with higher incidence compared to other studies ${ }^{20-25}$. Other symptoms are vomiting, dyspepsia, mass per abdomen $85.4 \%, \quad 43.9 \%$ and $2.4 \%$ respectively.

The predominant signs witnessed were pallor in 78\% (32 patients) and mass per abdomen in $41.5 \%$ (17 patients) which explain slow and aggressive nature of the disease. Other important signs noted are hepatomegaly, ascites, Virchow's node $(19.5 \%), 24.4 \%$ and $14.6 \%$ respectively $^{26}$. Risk factors like smoking and alcohol were noted in $51.2 \%$ (21 patients), $41.5 \%$ (17 patients) respectively ${ }^{26}$. 


\section{Conclusion}

Gastric cancer is an aggressive disease with rapidly progressing and high mortality. It becomes important to know the natural history of the disease for early diagnosis so that early and accurate treatment can be subjected. With this article we made an attempt to identify the common symptoms and signs of the Gastric cancer. As the results shows, if patients with gastric cancer are thoroughly evaluated with good clinical history and a careful examination of the patient many important symptoms and signs can be picked up which will help to subject the patients for further invasive evaluation and also helps in better prognosis of the disease.

\section{References}

1. T.W.Sadler: Digestive system. In, Susan katz (eds): Langman's medical embryology, $8^{\text {th }}$ Edn. Lippincott, William and wilkin's 2000; 270-76.

2. Rao DN, Ganesh B. Estimate of cancer incidence in India in 1991. Indian J Cancer 1998; 35:10-8.

3. Yeole BB. Trends in cancer incidence in esophagus, stomach, colon, rectum and liver in males in India. Asian Pac J Cancer Prev 2008; 9:97-100.

4. Satyanarayana L, Asthana S. Life time risk for development of ten major cancers in India and its trends over the years 1982 to 2000. Indian J Med Sci 2008; 62:35-44.

5. Rastogi T, Devesa S, Mangtani $\mathrm{P}$, et al. Cancer incidence rates among South Asians in four geographic regions: India, Singapore, UK and US. Int J Epidemiol 2008; 37:147-60.

6. Lawrence H, Bannister, Martin M, Berry: Gastrointestinal system in Gray's Anatomy $39^{\text {th }} \mathrm{Edn}$. Churchill livingstone 2008.1140- 1150.

7. Mercer DW, Liu TH, Castaneda A: Anatomy and physiology of the stomach, in Zuidema GD, Yeo CJ (eds): Shackelford's Surgery of the Alimentary
Tract, 5th ed., Vol. II. Philadelphia: Saunders, 2002, p 3. Copyright Elsevier.

8. David W. Mercer M.D.Emily K. Robinson M.D: Stomach in Sabiston Textbook of Surgery, 17th Edn. Saunders company 2004.1265-1312.

9. Moody F, McGreevy J, Miller T: Stomach. In Schwartz SI, Shires GT [eds]: Principles of Surgery, 5th ed. New York,McGrawHill, 1989.

10. Hermanek P, et al (eds): TNM Atlas: Illustrated Guide to the TNM/pTNM Classification of Malignant Tumours, 4th ed. Berlin: Springer-Verlag, 1997, p82-83.

11. Eslick GD. Helicobacter pylori infection causes gastric cancer? A review of the epidemiological, meta-analytic, and experimental evidence. World J Gastroenterol 2006; 12:2991-9.

12. Uemura N, Okamoto S, Yamamoto S, et al. Helicobacter pylori infection and the development of gastric cancer. N Engl J Med 2001; 345:784-9.

13. Huang JQ, Sridhar S, Chen Y, et al. Metaanalysis of the relationship between Helicobacter pylori seropositivity and gastric cancer. Gastroenterology 1998; 114:1169-79.

14. Schistosomes, liver flukes and Helicobacter pylori. IARC Working Group on the Evaluation of Carcinogenic Risks to Humans. Lyon, 7-14 June 1994. IARC MonogrEvalCarcinog Risks Hum 1994; 61:1-241.

15. Khan MI, Baqai MT, Bukhari M, Hashmi RI: Gastric carcinoma: 5 years survival after gastric surgery. J Pak Med Assoc 2005, 55:158-160.

16. Safaee A, Moghimi-Dehkordi B, Fatemi SR, et al. Clinicopathological Features of Gastric Cancer: A Study Based on Cancer Registry Data. IJCP 2009; 2:67-70.

17. Sasagawa T, Solano H, Mena F. Gastric cancer in Costa Rica. GastrointestEndosc 1999; 50:594-5; discussion 595-6. 
18. Yao JC, Tseng JF, Worah S, et al. Clinicopathologicbehavior of gastric adenocarcinoma in Hispanic patients: analysis of a single institution's experience over 15 years. J ClinOncol 2005; 23:3094103.

19. Sadjadi A, Malekzadeh R, Derakhshan $\mathrm{MH}$, et al. Cancer occurrence in Ardabil: results of a population-based cancer registry from Iran. Int J Cancer 2003; 107:113-8.

20. Kong SH, Park DJ, Lee HJ, et al. Clinicopathologic features of asymptomatic gastric adenocarcinoma patients in Korea. Jpn J ClinOncol 2004; 34:1-7.

21. Medina-Franco H, Heslin MJ, CortesGonzalez R. Clinicopathological characteristics of gastric carcinoma in young and elderly patients: a comparative study. Ann SurgOncol 2000; 7:515-9.

22. Rao DN, Ganesh B, Dinshaw KA, et al. A case-control study of stomach cancer in Mumbai, India. Int J Cancer 2002; 99:72731.

23. Eskandar H, Hossein SS, Rahim M, et al. Clinical profile of gastric cancer in Khuzestan, southwest of Iran. World J Gastroenterol 2006; 12:4832-5.

24. Plummer JM, Gibson TN, McFarlane ME, et al. Clinicopathologic profile of gastric carcinomas at theUniversity Hospital of the West Indies. West Indian Med J 2005; 54:364-8.

25. Kelley JR, Duggan JM. Gastric cancer epidemiology and risk factors. J ClinEpidemiol 2003; 56:1-9.

26. Joseph B Mabula, Mabula D Mchembe et al Gastric cancer at a university teaching hospital in northwestern Tanzania: a retrospective review of 232 cases. World Journal of Surgical Oncology 2012, 10:257 